\section{Combined use of narrow-band imaging magnifi- cation endoscopy and miniprobe confocal laser microscopy in neoplastic Barrett's esophagus}

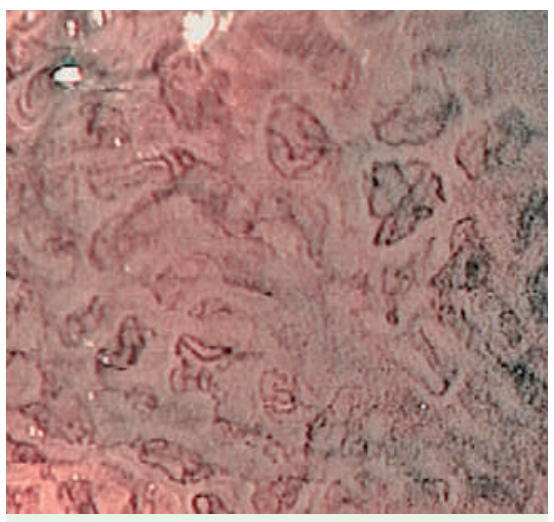

Fig. 1 Neoplastic Barrett's esophagus visualized by narrow-band imaging magnification endoscopy.

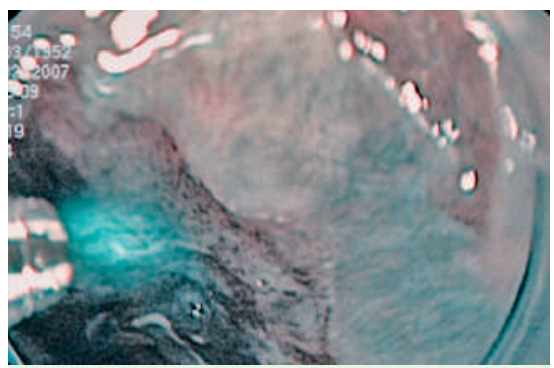

Fig. 2 Application of miniprobe confocal laser microscopy.

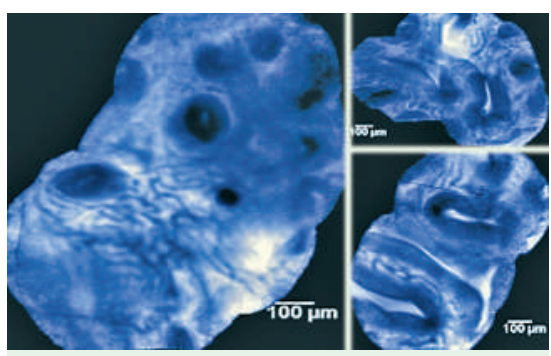

Fig. 3 Mosaic imaging of neoplastic Barrett's esophagus by miniprobe confocal laser microscopy. scope and mosaic imaging $[3,4]$.
S. Miehlke ${ }^{1}$, A. Morgner ${ }^{1}$, D. Aust ${ }^{2}$,

A. Madisch ${ }^{1}$, M. Vieth ${ }^{3}$, G. Baretton ${ }^{2}$

${ }^{1}$ Medical Department I, University Hospital Dresden, Dresden, Germany

2 Institute of Pathology, University Hospital Dresden, Dresden, Germany

3 Institute of Pathology, Klinikum Bayreuth, Bayreuth, Germany

The identification of intraepithelial neoplasia in Barrett's esophagus in cases where there are no visible focal lesions remains a challenge. Novel techniques such as narrow-band imaging-assisted magnification endoscopy or confocal laser microscopy could, however, improve the endoscopic detection of neoplasia in Barrett's esophagus [1,2]. A miniprobebased confocal laser microscopy system (Cellvizio-GI; Mauna Kea Technologies, Paris, France) became available recently which allows the application of laser microscopy with any conventional endo-

In this report we describe the combined use of these two techniques in two patients with long-segment Barrett's esophagus in whom previous random biopsies had led to a suspicion of neoplasia. First, narrow-band imaging magnification endoscopy (GIF-Q160Z; Olympus Optical Co., Tokyo, Japan) was performed and this identified multifocal mucosal abnormalities and irregular vessels ( Fig. 1) that were suggestive of neoplasia. Subsequently, $5 \mathrm{~mL}$ fluorescein $1 \%$ was injected intravenously and miniprobe confocal laser microscopy (Mauna Kea Technologies Cellvizio-GI ${ }^{\circledR}$ and Zprobe, confocal plane $100 \mu \mathrm{m}$ ) was applied via the working channel of the endoscope ( $\bullet$ Fig. 2). With confocal laser microscopy and mosaic imaging of multiple individual image frames, an highly irregular mucosal architecture, with enlarged glandular structures, highly irregular mucosal vessels, and so called "black cells" were visualized ( $\bullet$ Fig. 3). Targeted biopsies of the identified areas confirmed multifocal low-grade neoplasia in one patient and high-grade neoplasia in the other patient.

These cases demonstrate that the combined use of miniprobe confocal laser microscopy and narrow-band imaging magnification endoscopy is feasible. Further studies are necessary to investigate whether the detection of Barrett's neoplasia can be further optimized by the combined use of these novel techniques.

\section{References}

1 Kara MA, Ennahachi M, Fockens $P$ et al. Detection and classification of the mucosal and vascular patterns (mucosal morphology) in Barrett's esophagus by using narrow band imaging. Gastrointest Endosc 2006; 64: $155-166$

2 Kiesslich R, Gossner L, Goetz M et al. In vivo histology of Barrett's esophagus and associated neoplasia by confocal laser endomicroscopy. Clin Gastroenterol Hepatol 2006; 4: $979-987$

3 Meining A, Saur D, Bajbouj $M$ et al. In-vivo histopathology for detection of gastrointestinal neoplasia using a portable, confocal miniprobe - an examiner blinded analysis. Clincal Gastroenterol Hepatol 2007; in press

4 Becker V, Vercauteren T, Weyhern C von et al. High resolution miniprobe-based confocal microscopy in combination with video mosaicing. Gastrointest Endosc 2007; in press

\section{Bibliography}

DOI 10.1055/s-2007-966797

Endoscopy 2007; 39: E316

(c) Georg Thieme Verlag KG Stuttgart · New York . ISSN 0013-726X

\section{Corresponding author}

\section{S. Miehlke, MD}

Medical Department I

Technical University Hospital

Fetscherstrasse 74

01307 Dresden

Germany

Fax: +49-51-458-5859

stephan.miehlke@uniklinikum-dresden.de 